\title{
RESEARCH
}

Open Access

\section{Utilization profile of emergency department by irregular migrants and hospitalization rates: lessons from a large urban medical center in Tel Aviv, Israel}

\author{
S. Shachaf ${ }^{1,2^{*}}$, N. Davidovitch ${ }^{1}$, P. Halpern ${ }^{1,3}$ and Z. Mor ${ }^{3,4}$
}

\begin{abstract}
Background: Irregular migrants (IMM) are excluded from the National health insurance in most developed countries and may use the emergency department (ED) as a source for medical care.

This study aims to compare the use of ED by IM with that of Israeli citizens (IC) in a large urban hospital in Tel Aviv, including socio-demographic characteristics, hospitalization proportion and medical conditions on admission.

Methods: This cross-sectional study included all IM and IC patients older than 18 years who attended the ED between 2007 and 2011, and compared their socio-demographic characteristics, the administrative details of the visit and clinical variables upon admission. Hospitalization proportion was calculated by dividing the number of patients who were admitted to the hospital ward by the number of all patients who attended the ED.

Results: IM who attended the ED were younger compared to IC (mean $39 \pm 17$ versus $52 \pm 22$ years, respectively), mostly males (1.4 Male/Female ratio) and mainly originated from developing countries. IM were more commonly selfreferred, more likely to attend the ED during evening hours and weekends, complained of occupational injuries and frequented the surgical rather the medical ward of the ED compared with IC. IM stayed at the ED for longer periods than IC, yet the proportion of their hospitalization was lower than that of IC (19.4\% versus $23.5 \%$, respectively).

Conclusion: IM stayed in the ED for longer periods and were less likely to be admitted to the hospital wards, suggesting presentation of non-severe medical conditions or possible barriers in ensuring care continuity in the community following discharge. Minimizing the barriers of $I M$ to primary care in the community can reduce unnecessary referrals to the ED. Additionally, hospitals managements should respond to the highvolume of IM by shifting staff to busy hours and improving the communication with IM.
\end{abstract}

Keywords: Emergency department, Health insurance, Immigration, Israel, Undocumented migrants

* Correspondence: shachafs@post.bgu.ac.il

'Department of Health Systems Management, School of Public Health, Faculty of Health Sciences, Ben Gurion University of the Negev, POB 653, 8410501 Beer Sheva, Israel

${ }^{2}$ Department of Emergency Medicine, Tel Aviv Medical Center, Tel Aviv, Israel

Full list of author information is available at the end of the article

(c) The Author(s). 2020 Open Access This article is licensed under a Creative Commons Attribution 4.0 International License, which permits use, sharing, adaptation, distribution and reproduction in any medium or format, as long as you give appropriate credit to the original author(s) and the source, provide a link to the Creative Commons licence, and indicate if changes were made. The images or other third party material in this article are included in the article's Creative Commons licence, unless indicated otherwise in a credit line to the material. If material is not included in the article's Creative Commons licence and your intended use is not permitted by statutory regulation or exceeds the permitted use, you will need to obtain permission directly from the copyright holder. To view a copy of this licence, visit http://creativecommons.org/licenses/by/4.0/. The Creative Commons Public Domain Dedication waiver (http://creativecommons.org/publicdomain/zero/1.0/) applies to the data made available in this article, unless otherwise stated in a credit line to the data. 


\section{Background}

The World Health Organization estimated that there are $~ 214$ million international migrants globally [1]. Migration flows comprise a wide range of populations, such as laborers, refugees, students and irregular migrants (IM), while each has its own medical needs and unique levels of vulnerability. IM are foreign-born persons who entered the hosting country without permission [2]. IM in many developed countries are excluded from the national health insurance and their access to healthcare is limited. Even in countries where the access to health care is guaranteed to migrants, IM may still be confronted with barriers precluding the optimized use of medical care [3]. These barriers include cultural gaps, language difficulties, different health perceptions and additional administrative and structural obstacles [4]. The limited access of IM to primary and preventive healthcare services in the community forces the migrants to seek for medical care through alternative routes, such as emergency departments (ED) for urgent and serious medical conditions, but also for non-severe medical conditions [5]. For example, IM in Spain were using ED services more commonly than Spanish born in a rate ratio of 1.4 for males and 2.2 for females [6]. In another systematic review performed in European countries, migrants were more likely to present to the ED during off-office hours and more likely than non-migrants to use the ED for low-acuity presentations [7].

The medical staff in the ER is supposed to assess the medical condition and treat IM, and also to respond to various social determinants of health influencing the medical conditions of the migrants. For example, the staff should understand the occupational exposures of the IM to certain diseases or risk for on-job injuries, and to respond to social and economic aspects related to their ability to follow the medical recommendation after discharge due to poor housing conditions and insecure employment. Additionally, hospital managements may be concerned with the limited ability of the migrants to pay for the services, especially in cases of hospitalization, as admissions are costly and are often not reimbursed by7 the IM [8]. The providers in the ED who are

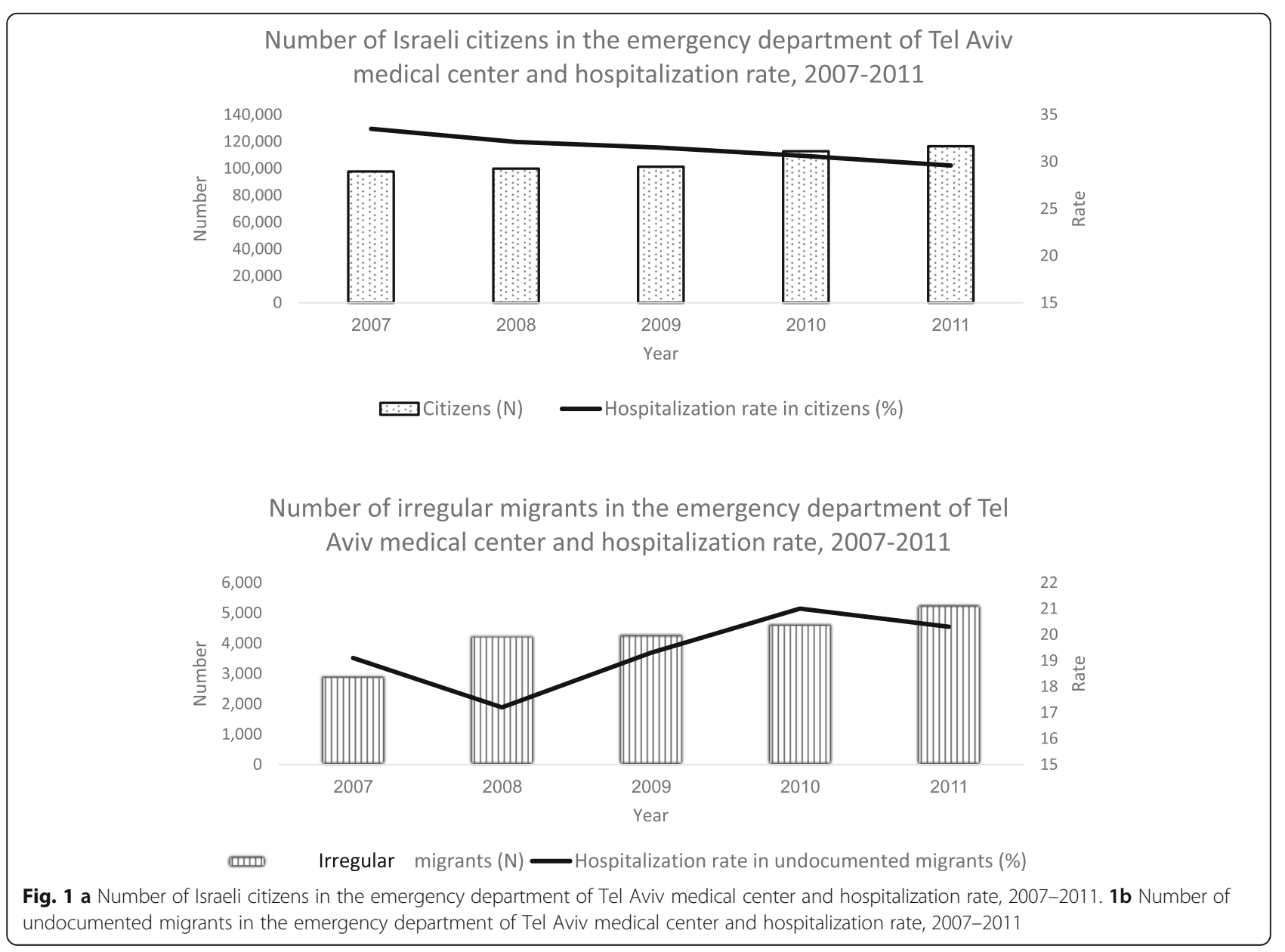


considering hospitalizing IM are confronted with conflicting challenges- the inadequate medical care in the community on one side, and limited ability of IM to pay for the hospital charge on the other side.

Israel absorbs all Jewish migrants under the law of return [9]. Those migrants are naturalized upon arrival and included in the national health and welfare insurance schemes form the first day. IM in Israel are not entitled for those benefits and are excluded from the Israeli national insurance law. However, based on the Patients Health Rights Law [10], they can refer to ED for urgent medical care for a fee. IM can also use two free community clinics in Tel Aviv. A pervious study reported that those clinics mainly provide primary care, but are facing difficulties to respond to patients with complex medical conditions or chronic diseases due to lack of qualified medical staff or insufficient diagnostic equipment [11].
It is estimated that more than 60,000 migrants who originated from the horn of Africa (especially Eritrea and Sudan) have entered Israel, who are mostly residing in the poorest neighborhoods of Tel Aviv [12]. The Tel Aviv Sourasky Medical Center (TASMC) is the second largest hospital in Israel and is situated in the heart of the city. It therefore provides the main medical site for emergency care for the IM.

This study aimed, for the first time in Israel, to assess the use of ED services by IM and compare the presenting medical conditions, care provided at the ED and hospitalization proportion between IM and Israeli citizens (IC). In line with previous publications from other developed countries which have exclusive national health insurance for citizens [13-17], our study hypothesis was that the proportion of hospitalization of IM would be lower than IC due to the cost of hospitalization and the

Table 1 Demographic characteristics of patients visited the emergency department by civil status, 2007-2011

\begin{tabular}{|c|c|c|c|c|}
\hline \multirow{2}{*}{$\begin{array}{l}\text { Visitor type } \\
\text { Characteristic }\end{array}$} & \multicolumn{2}{|c|}{ Irregular migrants $\boldsymbol{N}=21,495(\%)$} & \multicolumn{2}{|c|}{ Israeli Citizens $\boldsymbol{N}=528,218(\%)$} \\
\hline & Male & Female & Male & Female \\
\hline \multicolumn{5}{|l|}{ Age groups (years) } \\
\hline $18-34$ & $6839(54.4)$ & $4313(48.3)$ & $79,752(30.0)$ & $77,224(29.5)$ \\
\hline $35-49$ & $3127(24.9)$ & $2038(22.8)$ & $57,833(21.7)$ & $44,811(17.1)$ \\
\hline $50-64$ & $1440(11.5)$ & $1482(16.6)$ & $53,063(20.0)$ & $48,735(18.6)$ \\
\hline $65+$ & $1161(9.2)$ & $1095(12.3)$ & $75,564(28.3)$ & $91,236(34.8)$ \\
\hline \multicolumn{5}{|l|}{ Male: female ratio } \\
\hline $18-34$ & 1.6 & & 1.0 & \\
\hline $35-49$ & 1.5 & & 1.3 & \\
\hline $50-64$ & 1.0 & & 1.1 & \\
\hline $65+$ & 1.1 & & 0.8 & \\
\hline Overall & 1.4 & & 1.0 & \\
\hline \multicolumn{5}{|l|}{ Area of origin } \\
\hline Asia and Oceania & $536(4.3)$ & $825(9.2)$ & $2488(0.9)$ & $3044(1.2)$ \\
\hline East Europe & $494(3.9)$ & $572(6.4)$ & $58,763(22.1)$ & $69,726(26.6)$ \\
\hline West Europe & $637(5.0)$ & $552(6.2)$ & $7710(2.9)$ & $9800(3.7)$ \\
\hline North Africa and the Middle East & $162(1.3)$ & $61(0.7)$ & $31,112(11.7)$ & $32,147(12.3)$ \\
\hline Horn of Africa & $2916(23.2)$ & $743(8.3)$ & $1409(0.5)$ & $1030(0.4)$ \\
\hline Africa, south of the Sahara & $446(3.5)$ & $259(2.9)$ & $852(0.3)$ & $790(0.3)$ \\
\hline America & $486(3.9)$ & $476(5.3)$ & $5676(2.1)$ & $6701(2.6)$ \\
\hline Israel & - & - & $155,787(58.5)$ & $136,754(52.2)$ \\
\hline Unregistered & $6890(54.8)$ & $5440(60.9)$ & $2415(0.9)$ & $2014(0.7)$ \\
\hline \multicolumn{5}{|l|}{ Residential district } \\
\hline Northern Israel & $104(0.8)$ & $53(0.6)$ & $12,264(4.6)$ & $7468(2.9)$ \\
\hline Jerusalem & $135(1.1)$ & $111(1.2)$ & $4898(1.8)$ & $3213(1.2)$ \\
\hline Tel Aviv & $9718(77.3)$ & $7523(84.3)$ & 208,394 (78.3) & $215,456(82.2)$ \\
\hline Central Israel & $465(3.7)$ & $295(3.3)$ & $31,998(12)$ & $28,644(10.9)$ \\
\hline Southern Israel & $195(1.6)$ & $87(1)$ & $8111(3)$ & $6777(2.6)$ \\
\hline Unknown & $1950(15.5)$ & 859 (9.6) & $547(0.2)$ & $448(0.2)$ \\
\hline
\end{tabular}


self-loss of working time. The findings of this study will support the managerial level in hospitals and decision makers at the Ministry of Health in designing medical services which meet the unique needs of IM.

\section{Methods}

This cross-sectional study included all IM and IC patients older than 18 years of age who attended the adult section of the ED at the TASMC between January 1st 2007 and December 31st 2011, during the major mmigration flux of IM into Israel. The data were available from the computerized registration files. Patients who were referred to the gynecological or the pediatric wards of the ED were excluded from this study. IM were defined as non-Israeli citizens without medical insurance, whereas IC were defined as citizens or residents who were insured by the national health insurance law, regardless their country of origin. Data collected for this study included socio-demographic characteristics (age, gender, continent or area of origin and residential district), administrative details (time of arrival and discharge from the ED, division where the patients were treated, mode of referral) and clinical variables (presenting medical condition upon admission to the ED and the outcome of the ED visit). Hospitalization proportion was calculated by dividing the number of patients who were admitted to the hospital ward by the number of all patients who attended the ED from each group. Time spent in the ED was measured from the time of registration to the time of release (whether discharge to the community or admission to one of the hospital's wards).

\section{Statistical analysis}

Risk factors that affected ED visits were identified by logistic regression using generalized estimating equation multivariable model, which included all the independent characteristics that were statistically in the univariate analysis. Due to the gender differences between IM and IC, a shared model was performed by matching IM and IC according to gender, age ( \pm 4 years differences) and for the year of the visit. The group matching included 28,871 pairs. The association between the visitor type (IM/IC) and the likelihood of being hospitalized from the ED was tested using conditional logistic regression.

SPSS (v 20.0) was used for the statistical analyses.

\section{Results}

Between 2007 and 2011, 549,713 attendances were recorded at the adult ED of the TASMC, of which 528,218 (96.1\%) were IC and 21,495 (3.9\%) were IM. Of all the patients who visited the ED, 169,878 (30.9\%) were admitted to one of the hospital's wards: 165,697 (97.5\%) were IC and 4181 (2.5\%) were IM.

The number of visits of IM to ED increased during the study period, yet their average hospitalization proportion was significantly lower than that of IC (19.4\% versus
$23.5 \%$, respectively, $p<0.001$, Fig. $1 \mathrm{a}$ and $\mathrm{b})$. IM who visited the ED were younger than IC and their mean age was 39 years $(\mathrm{SD}=17)$ compared with 52 years $(\mathrm{SD}=22)$ for IC. The majority of IM who visited the ED were males, who originated from horn of Africa and resided in Tel Aviv (Table 1).

IM were more likely to be treated in the surgical ward of the ED than IC, more commonly attended the ED during the evening shifts and weekends (Fridays and Saturdays in Israel) (Table 2). Most IM self-referred themselves to the ED, and were more likely to complain of occupational injuries and violence than IC (28.8\% vs.

Table 2 Administrative characteristics of patients visited the emergency department by civil status, 2007-2011

\begin{tabular}{|c|c|c|}
\hline Characteristic & $\begin{array}{l}\text { Irregular migrants } \\
N=21,495(\%)\end{array}$ & $\begin{array}{l}\text { Israeli Citizens } \\
N=528,218(\%)\end{array}$ \\
\hline \multicolumn{3}{|l|}{ ED division } \\
\hline Internal medicine & $8835(41.1)$ & $244,737(46.3)$ \\
\hline Surgical & $12,660(58.9)$ & $283,481(53.7)$ \\
\hline \multicolumn{3}{|l|}{ Shift } \\
\hline Morning (7:00 AM - 3:00 PM) & $8632(40.2)$ & $240,873(45.6)$ \\
\hline Evening (3:00 PM - 11:00 PM) & $9051(42.1)$ & $204,080(38.6)$ \\
\hline Night (11:00 PM - 7:00 AM) & $3812(17.7)$ & $83,265(15.8)$ \\
\hline \multicolumn{3}{|l|}{ Day of the week } \\
\hline Sunday & $3585(16.7)$ & $90,356(17.1)$ \\
\hline Monday & $3120(14.5)$ & $79,627(15.1)$ \\
\hline Tuesday & $3066(14.3)$ & $78,681(14.9)$ \\
\hline Wednesday & $3075(14.3)$ & $76,799(14.5)$ \\
\hline Thursday & $3026(14.1)$ & $79,803(15.1)$ \\
\hline Friday & $2832(13.2)$ & $66,244(12.5)$ \\
\hline Saturday & $2791(13.0)$ & $56,708(10.7)$ \\
\hline \multicolumn{3}{|l|}{ Mode of referral } \\
\hline Self-referral & $13,777(64.1)$ & $203,699(38.6)$ \\
\hline Health institute & 7447 (34.6) & $321,964(61)$ \\
\hline Employer & $271(1.3)$ & $2555(0.5)$ \\
\hline \multicolumn{3}{|l|}{ Patient complaint } \\
\hline Illness & $14,491(67.6)$ & $381,634(72.2)$ \\
\hline Road accident & $578(2.7)$ & $30,716(5.8)$ \\
\hline Occupational accident & $5108(23.8)$ & $98,927(18.8)$ \\
\hline Violence & $1040(4.8)$ & $5954(1.1)$ \\
\hline Unknown & $235(1.1)$ & $10,987(2.1)$ \\
\hline \multicolumn{3}{|c|}{ Length of stay in ED (average hours \pm Standard deviation) } \\
\hline \multicolumn{3}{|c|}{ Visits ended with discharge from the ED } \\
\hline Male & $3.04 \pm 2.36$ & $2.87 \pm 2.23$ \\
\hline Female & $3.14 \pm 2.41$ & $3.03 \pm 2.28$ \\
\hline \multicolumn{3}{|c|}{ Visits ended with hospital admission } \\
\hline Male & $2.95 \pm 2.21$ & $2.50 \pm 1.87$ \\
\hline Female & $3.14 \pm 2.34$ & $2.62 \pm 1.93$ \\
\hline
\end{tabular}


18.8 , and $4.8 \%$ vs. $1.1 \%$, respectively). However, in cases IM were referred to the ER by health providers, they were more likely to be hospitalized than IC. IM also stayed in the ED for longer periods, regardless whether they were hospitalized or discharged to the community.

Male IM were more likely to be hospitalized than females $(61.9 \%$ versus $38.1 \%$ of the hospitalized IM, respectively, $p<0.001)$, whereas the gender ratio of hospitalization of IC was similar for both genders $(51.1 \%$ versus $48.9 \%$, respectively, $p=0.1$ ). The proportion of hospitalization of the IM generally increased with age, whereas the rate among IC was stable throughout the different age groups (Fig. 2).

Factors which increased the likelihood of hospitalization among IM included being male, older age, living outside of the city of Tel Aviv, being treated at the internal ward of the
ED, attending the ED between 2009 and 2011, arriving during the evening shift and on working days and being referred by a health provider- generally similar to IC (Table 3). Logistic regression analysis adjusted for the origin of the patient, the treating ward in the ED, the daily shift, mode of referral, patient's complaint and length of stay demonstrated that IM were less likely to be hospitalized than IC (Table 4).

The mean duration of hospitalization for IM aged 18-49 years was longer by one day and $14 \mathrm{~h}$ than that of that of IC in similar ages.

\section{Discussion}

IM comprised $\sim 4 \%$ of all individuals who visited the ED of the TASMC and $2.5 \%$ of its hospitalized patients. IM stayed in the ED for a longer time than IC before being

\section{a: Distribution of male hospitalization by civil status, 2007-2011}

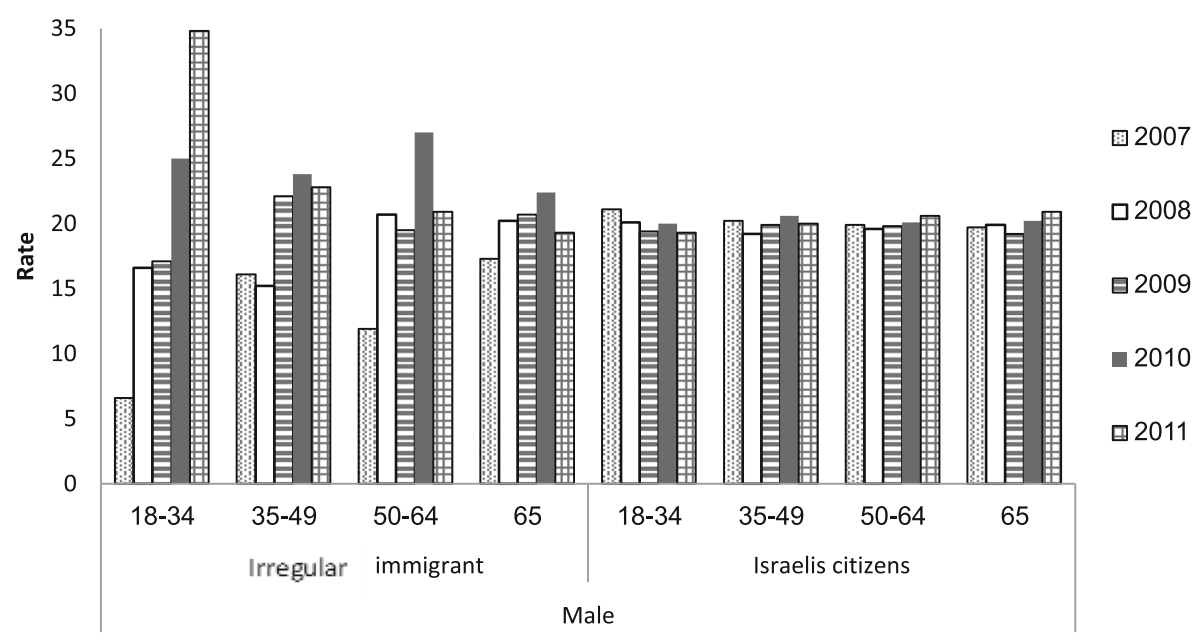

b: Distribution of female hospitalization by civil status, 2007-2011

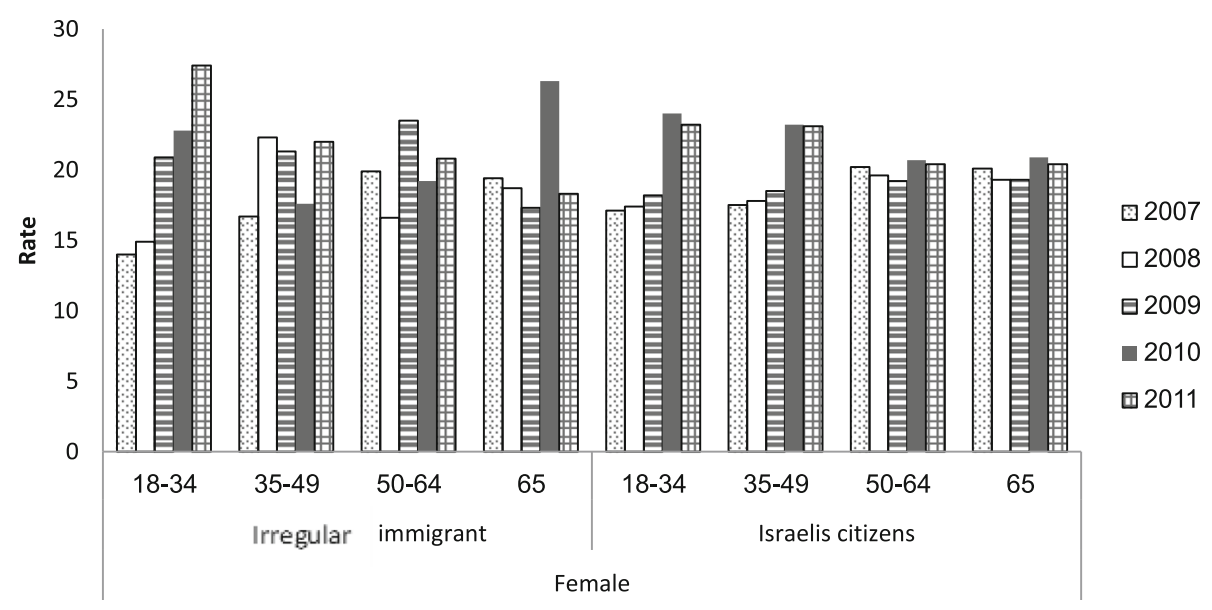

Fig. 2 a: Distribution of male hospitalization rate by civil status, 2007-2011. b: Distribution of female hospitalization rate by civil status, 2007-2011 
Table 3 Factors associated with patient hospitalization from emergency department - generalized estimating equations (GEE)

\begin{tabular}{|c|c|c|c|c|c|}
\hline \multirow[b]{2}{*}{ Characteristic } & \multirow[b]{2}{*}{ Categories } & \multicolumn{2}{|c|}{$\begin{array}{l}\text { Irregular migrants } \\
N=21,495(\%)\end{array}$} & \multicolumn{2}{|c|}{$\begin{array}{l}\text { Israeli Citizens } \\
N=528,218(\%)\end{array}$} \\
\hline & & OR $(95 \% \mathrm{Cl})$ & $P$-Value & OR $(95 \% \mathrm{Cl})$ & P-Value \\
\hline \multirow[t]{2}{*}{ Gender } & Male & $1.4(1.2-1.5)$ & $P<0.001$ & $1.5(1.4-1.6)$ & $P<0.001$ \\
\hline & Female & 1 & & 1 & \\
\hline Age (year) & & $1.1(1.1-1.2)$ & $P<0.001$ & $1.0(1.0-1.0)$ & $P<0.001$ \\
\hline \multirow[t]{2}{*}{ Residential district } & Other than Tel Aviv & $1.4(1.3-1.5)$ & $P<0.001$ & $1.4(1.2-1.7)$ & $P<0.001$ \\
\hline & Tel Aviv & 1 & & 1 & \\
\hline \multirow[t]{2}{*}{ ED division } & Internal medicine & $1.5(1.3-1.6)$ & $P<0.001$ & $1.8(1.6-1.8)$ & $P<0.001$ \\
\hline & Surgical & 1 & & 1 & \\
\hline \multirow[t]{2}{*}{ Year of the visit } & $2007-2008$ & $1.05(1.0-1.1)$ & $P<0.004$ & $0.9(0.9-1.0)$ & $P<0.001$ \\
\hline & 2009-2011 & 1 & & 1 & \\
\hline \multirow[t]{3}{*}{ Shift } & Evening & $1.1(1.0-1.3)$ & $P<0.005$ & $1.0(1.0-1.0)$ & $P<0.006$ \\
\hline & Night & $1.0(0.9-1.2)$ & $P<0.661$ & $0.9(0.9-1.0)$ & $P<0.001$ \\
\hline & Morning & 1 & & 1 & \\
\hline \multirow[t]{3}{*}{ Day of the week } & Sunday & $1.1(1.05-1.2)$ & $P<0.045$ & $1.2(1.1-1.2)$ & $P<0.000$ \\
\hline & Monday-Thursday & $1.1(1.04-1.2)$ & $P<0.043$ & $1.1(1.1-1.2)$ & $P<0.001$ \\
\hline & Friday-Saturday & 1 & & 1 & \\
\hline \multirow[t]{3}{*}{ Mode of referral } & Health institute & $2.5(2.2-2.7)$ & $P<0.001$ & $1.5(1.4-1.6)$ & $P<0.001$ \\
\hline & Employer & $0.2(0.1-0.6)$ & $P<0.005$ & $0.4(0.4-0.5)$ & $P<0.001$ \\
\hline & Self-referral & 1 & & 1 & \\
\hline \multirow[t]{5}{*}{ Patient complaint } & Violence & $0.6(0.4-0.9)$ & $P<0.004$ & $0.9(0.8-1.0)$ & $P<0.003$ \\
\hline & Industrial accident & $0.4(0.3-0.5)$ & $P<0.001$ & $0.3(0.2-0.3)$ & $P<0.001$ \\
\hline & Road accident & $0.5(0.3-0.9)$ & $P<0.009$ & $0.3(0.3-0.3)$ & $P<0.001$ \\
\hline & Unknown & $2.7(2.0-3.8)$ & $P<0.001$ & $1.3(1.2-1.4)$ & $P<0.001$ \\
\hline & Illness & 1 & & 1 & \\
\hline Average length of stay in ED until discharge or hospitalization (hour) & & $0.9(0.9-0.9)$ & $P<0.013$ & $0.9(0.8-0.8)$ & $P<0.001$ \\
\hline
\end{tabular}

discharged, yet their hospitalization proportion was lower.

The ED functions as a medical site for urgent and severe medical conditions, such as life-threatening events and other major injuries. However, because IM have limited access to ambulatory treatment alternatives, they may refer themselves to the ED also for non-severe medical conditions. This high volume of IM self-referral is likely to reflect a limited access to primary care, possible inadequate orientation of the alternative ambulatory treatment sites, dissatisfaction with previous providers in the community and the anticipation for rapid diagnosis and treatment. Additionally, language barriers, financial constraints, health literacy and lack of understanding of the healthcare system may inhibit IM to use community services [7]. The ED management is facing an increased demand of individuals who seek for medical care in the ED, while balancing between the hospitals' responsibility to provide emergency care and at the same time to serve as a "safety medical net" for IM who can not get medical services in the community [18].
As expected, IM in our study were younger than IC, mostly in their working years and the majority were males. Evening hours and weekends were the preferred times for IM to attend the ED. This may be related to their work duties during the week, while trying not to miss paid days, thus using off-office hours to seek for medical services at the ED. Contrarily, IC enjoy labor rights and are eligible to take a paid sick leave and visit their medical providers during working hours. The relatively lower proportion of hospitalization of the IM compared with that of IC may suggest that their presenting medical conditions in the ER were milder and did not require intense care. This may be aligned with their younger age compared to IC. It is also possible that IM were hospitalized due to financial difficulties, as they are supposed to pay for the hospital care. Migrants may also refrain from hospitalization as they are missing working days which affect their income. Better access of IM to ambulatory care with more flexible hours may have reduced the volume of cases who attend the ER. The estimated male:female IM ratio in Israel is 5:1 [19], which 
Table 4 Factors influencing patient hospitalization from the emergency department - conditional logistic regression

\begin{tabular}{llll}
\hline Characteristic & Categories & OR (95\% Cl) & $P$-Value \\
\hline Visitor type & Irregular migrants & $0.8(0.7-0.9)$ & $P<0.001$ \\
& Israeli citizens & 1 & \\
ED division & Internal & $1.4(1.3-1.5)$ & $P<0.001$ \\
& Surgical & 1 & \\
Shift & Evening & $0.9(0.9-1.0)$ & N.S \\
& Night & $0.9(0.8-0.9)$ & $P<0.000$ \\
Day of the week & Morning & 1 & \\
& Sun & $1.1(1.0-1.2)$ & $P<0.005$ \\
& Mon-Thu & $1.1(1.0-1.2)$ & $P<0.002$ \\
Mode of referral & Fri-Sat & 1 & \\
& Health institute & $1.7(1.6-1.8)$ & $P<0.001$ \\
& Employer & $0.5(0.3-0.8)$ & $P<0.008$ \\
Patient complaint & Self-referral & 1 & \\
& Violence & $0.7(0.6-0.9)$ & $P<0.003$ \\
& Industrial accident & $0.3(0.3-0.4)$ & $P<0.001$ \\
& Road accident & $0.2(0.2-0.3)$ & $P<0.001$ \\
& Unknown & $1.6(0.9-2.8)$ & $P<0.066$ \\
& Illness & 1 & \\
\hline
\end{tabular}

may explain the lower volume of women referred to the ER. However, females' hospitalization rate in our study was lower than that of males. This might reflect employment instability of women IM compared with that of men, and also be related to gender family commitments which resulted in limited time and opportunities for hospitalization [20].

IM complained of more occupational injuries than IC, and consequently were treated in the surgical ward of the ED. IM are generally more likely to work in jobs that expose the workers to risks [21], which are also referred as "3-D jobs" (Dirty, Dangerous, Demanding) [22]. Moreover, their employment is mostly "off-the-books", without sufficient training and tutelage work safety.

The total length of the visit of IM in the ED was longer than that of IC. This may be of particular significance, as ED are generally overcrowded [23]. It is possible that medical staff were lacking previous medical history of IM, faced language and communication barriers with the patients and were confronted with different cultural perspective regarding health and illness [24]. The lack of previous medical information might have led to longer time spent in the ED and the need to rely on diagnostic tests, which prolonged the time required for physicians' decision [25]. It also may be that physicians in the ED who initially planned to admit the patient in the hospital postponed the transfer, while trying to stabilize the medical condition. If the patient's medical condition had been stabilized in the ED, she/he could have been discharged to the community, sparing the hospitalization costs. We further calculated that during the study period, all the IM stayed in the ED for a total of $2397 \mathrm{~h}$, which is equivalent to 40 additional hours a month.

The volume of IM who use the ED, especially for routine non-severe medical conditions presents a unique challenges to the hospitals' administrations, as found in other developed countries [13-17, 26]. The medical staff at the ED have to function under additional pressure, while increasing the possibility for clinical errors to occur and reducing patients' level of satisfaction [27]. Furthermore, ED visits are costly and in cases the IM is unable to pay for the service, the hospital is not reimbursed. A financial estimation which was performed in the TASMC in 2012 found that US $\$ 5,670,103$ of accumulated IM debts from unpaid ED visits and hospitalizations were not collected [28].

This is the first study performed in Israel to assess the use of ED by IM, yet it is subject to several limitations. First, the data were originally collected for administrative purposes up to 2011, and therefore specific health determinants, such as profession, education, income, living condition and complete medical records were not included. Second, IM do not have identification numbers and their names are sometime difficult to spell by the local staff. It was therefore difficult to define recurrent visits with first referral to the ED. Third, IM are usually generally younger than the general population in the hosting country and therefore are exposed to different risk and have other medical conditions. Lastly, female IM can also be hospitalized after visiting the gynecology ED, which was not captured in this study. It is therefore likely that actual female hospitalization rate was higher.

The results of this study may be used by hospitals management to improve the medical services in the ED in order to meet the migrants' health needs, as was developed in Geneva, where a "migrant friendly" institutional culture was embedded in the hospital operational scheme [29]. For example, using a triage nurse with ability to speak several languages in order to perform a rapid clinical classification of the visits and to recommend the IM with mild medical conditions other treatment alternatives in the community. A translator in the ED may assist the medical staff in taking patients' history and providing recommendations. Better staffing of the $E D$, especially in the surgical ward of the ED and on evening shifts and weekends may reduce the overload of the medical staff at the ED. On the national level, decision makers should consider granting the IM a "social residency" [30], which is unrelated to their legal status, yet entitle them to health services. This way, they can 
use more services in the community, precluding unnecessary visits to the ED.

\section{Conclusions}

The hospitalization rates of IM in Israel were lower than that of citizens, and they may use the ED for non-severe medical conditions that could have been cared for in the community. In order to address the medical needs of the IM who are excluded from the national medical insurance, the access of the migrants to ambulatory community care should be improved.

\section{Abbreviations}

ED: Emergency department; IC: Israeli citizen; IM: Irregular migrant; TASMC: The Tel Aviv Sourasky Medical Center

\section{Acknowledgements}

N/A

\section{Authors' contributions}

SS initiate the study, collected, analyzed the data and wrote the first draft. ZM analyzed the data and had major contribution in writing the manuscript. $\mathrm{PH}$ assisted in data collection. ND assisted in summarizing the findings and the conclusions. All authors read and approved the final manuscript.

\section{Funding}

No funding was used for this research.

\section{Availability of data and materials}

The datasets used and/or analysed during the current study are available from the corresponding author on reasonable request.

\section{Ethics approval and consent to participate}

The study received ethical approval from the Institutional Review Board of the TASMC.

\section{Consent for publication}

Not applicable, the database did not include any identification details of the patients.

\section{Competing interests}

The authors declare that they have no competing interests.

\section{Author details}

'Department of Health Systems Management, School of Public Health, Faculty of Health Sciences, Ben Gurion University of the Negev, POB 653, 8410501 Beer Sheva, Israel. ${ }^{2}$ Department of Emergency Medicine, Tel Aviv Medical Center, Tel Aviv, Israel. ${ }^{3}$ Faculty of Medicine, Tel Aviv University, Tel Aviv, Israel. ${ }^{4}$ School of Health Sciences, Ashkelon Academic College, Ashkleon, Israel.

Received: 24 September 2019 Accepted: 2 March 2020

Published online: 29 April 2020

\section{References}

1. World Organization for Migration. World Migration Report 2018. Geneva, Switzerland, 2018

2. International Organization for Migration. Glossary on Migration. IOM Geneva, Switzerland, 2019. Available on: http://www.publications.iom.int/ system/files/pdf/iml_34_glossary.pdf. Accessed 5 Jan 2020.

3. Lee $\mathrm{S}, \mathrm{Choi} \mathrm{S}$. Disparities in access to health care among non-citizens in the United States. Health Sociol Rev. 2009;18(3):307-20.

4. Derose KP, Bahney BW, Lurie N, Escarce JJ. Immigrants and health care access, quality, and cost. Med Care Res Rev. 2009;66(4):355-408.

5. Afilalo J, Marinovich A, Afilalo M, Colescone A, Leger R, Unger B, Giguaere C. Nonurgent emergency department patient characteristics and barriers to primary care. Acad Emerg Med. 2004;11(12):1302-10.
6. Rué M, Cabré G, Soler-González J, Bosch a, Almirall M, Serna MC. Emergency hospital services utilization in Lleida (Spain): a cross-sectional study of immigrant and Spanish-born populations. BMC Health Serv Res. 2008:8:81.

7. Crede SH, Such E, Mason S. International migrants' use of emergency departments in Europe compared with non-migrants' use: a systematic review. Eur J Pub Health. 2017;28(1):61-73.

8. Ang JW, Chia C, Koh CJ, et al. Healthcare-seeking behaviour, barriers and mental health of non-domestic migrant workers in Singapore. BMJ Glob Health. 2017;2(2):e000213.

9. Israeli Parliament. Available on: https://www.knesset.gov.il/laws/special/eng/ return.htm Accessed January 52020.

10. State of Israel, Ministry of Justice. Patients Right law 1996. Available on: https://www.health.gov.il/English/Topics/RightsInsured/RightsUnderLaw/ Pages/default.aspx Accessed on October 102018.

11. Mor Z, Raveh Y, Lurie I, Leventhal A, Gamzu R, Davidovich N, Benari O, Grotto I. Medical condition and care of undocumented migrants in ambulatory clinics in Tel Aviv, Israel. Assessing unmet needs. BMC Health Serv Res. 2017;17(1):484.

12. Israeli population and immigration authority. 2017 Report. Jerusalem, Israel. Available on: https://www.gov.il/BlobFolder/reports/foreign_workers_in_ israel_summary_2017/he/foreigners_in_Israel_data_2017_1.pdf Accessed on October 102018.

13. Klein J, von der Knessebeck $O$. Inequalities in health utilization among migrants and non-migrants in Germany: as systematic review. Int J Equity Health. 2018;17(1):160

14. Johansson B, Helggesson M, Lundberg I, et al. Work and health among immigrants and natives swedes 19990-2008: a register=based study on hospitalization for common potentially work related disorders, disability pension and mortality. BMC Pub Health. 2012;12:845.

15. Ng E, Sanmartin C, Manuel DG. Hospitalization rates among economic immigrants to Canada. Health Rep. 2017;18(7):3-10.

16. Baglio G, Saunders C, Spinelli A, Osborn J. Utilization of hospital services in Italy: a comparative analysis of immigrants and Italian citizens. J Immigrant Minority Health. 2010;12:598-609.

17. Norredam M, Krasnik A, Moler Sorendsen T, Keiding N, Joost Michaelsed J, Sonne NA. Emergency room utilization in Copenhagen: a comparison of immigrant group and Danish born residents. Scand J Public Health. 2004; 32(1):53-9.

18. Tarraf W, Vega W, González HM. Emergency department services use among immigrant and non-immigrant groups in the United States. J Immigr Minor Health. 2014;16(4):595-606.

19. Israeli immigration and population authority. Labor migration to Israel, 2016. https://www.gov.il/BlobFolder/reports/foreign_workers_in_israel_2016_report/ he/foreign_workers_israel_review_0916.pdf Accessed on January 52020.

20. Gea-Sánchez M, Alconada-Romero Á, Briones-Vozmediano E, et al. Undocumented immigrant women in Spain: a scoping review on access to and utilization of health and social services. J Immigrant Minority Health. 2017;19:194

21. Orrenius PM, Zavodny M. Do immigrants work in riskier jobs? Demography. 2009;46(3):535-51.

22. Gransow B. Migrants and health in urban China (Vol. 38). In: Zhang HX, editor. Rural; Libinghood in China: Political economy in transition. New York: Routledge Publishers; 2015.

23. Herring A, Wilper A, Himmelstein DU, Woolhandler S, Espinola JA, Brown DF, Camargo CA Jr. Increasing length of stay among adult visits to US emergency departments, 2001-2005. Acad Emerg Med. 2009;16(7):609-16.

24. Petersen LA, Burstin HR, O'Neil AC, Orav EJ, Brennan TA. Nonurgent emergency department visits: the effect of having a regular doctor. MedCare. 1998;36(8):1249-55.

25. Baker LC, Baker LS. Excess cost of emergency department visits for nonurgent care. Health Aff (Millwood). 1994;13(5):162-71.

26. Mahmoud I, Hou XY. Immigrants and the utilization of hospital emergency departments. World J Emerg Med. 2012;3(4):245-50.

27. Taylor C, Benger JR. Patient satisfaction in emergency medicine. Emerg Med J. 2004;21(5):528-32.

28. Moshe N. Health Services for Foreign Workers and for Status-less Civilians. Knesset Center for Research and Information, 2013. http://www.knesset.gov. il/mmm/data/pdf/m03198.pdf Accessed on 6 September 2017.

29. Hudelson P, Dao MD, Perneger T, Durieux PS. A migrant friendly hospital initiative in Geneva, Switzerland: evaluation of the effects on staff knowledge and practices. PloS One. 2014;999:e106758. 
30. Fleischman Y, Willen SS, Davidovitch N, Mor Z. Migration as a social determinant of health for irregular migrants: Israel as case study. Soc Sci Med. 2015;147:89-97.

\section{Publisher's Note}

Springer Nature remains neutral with regard to jurisdictional claims in published maps and institutional affiliations.

Ready to submit your research? Choose BMC and benefit from:

- fast, convenient online submission

- thorough peer review by experienced researchers in your field

- rapid publication on acceptance

- support for research data, including large and complex data types

- gold Open Access which fosters wider collaboration and increased citations

- maximum visibility for your research: over $100 \mathrm{M}$ website views per year

At BMC, research is always in progress. 